University of Nebraska - Lincoln

DigitalCommons@University of Nebraska - Lincoln

USDA Wildlife Services - Staff Publications

U.S. Department of Agriculture: Animal and Plant Health Inspection Service

2010

Utility of livestock-protection dogs for deterring wildlife from cattle farms

Thomas M. Gehring

Central Michigan University, gehri1tm@cmich.edu

Kurt C. Vercauteren

USDA-APHIS-Wildlife Services, kurt.c.vercauteren@usda.gov

Megan L. Provost

Central Michigan University

Anna C. Cellar

Central Michigan University

Follow this and additional works at: https://digitalcommons.unl.edu/icwdm_usdanwrc

Gehring, Thomas M.; Vercauteren, Kurt C.; Provost, Megan L.; and Cellar, Anna C., "Utility of livestockprotection dogs for deterring wildlife from cattle farms" (2010). USDA Wildlife Services - Staff Publications. 1344.

https://digitalcommons.unl.edu/icwdm_usdanwrc/1344

This Article is brought to you for free and open access by the U.S. Department of Agriculture: Animal and Plant Health Inspection Service at DigitalCommons@University of Nebraska - Lincoln. It has been accepted for inclusion in USDA Wildlife Services - Staff Publications by an authorized administrator of DigitalCommons@University of Nebraska - Lincoln. 


\title{
Utility of livestock-protection dogs for deterring wildlife from cattle farms
}

\author{
Thomas M. Gehring ${ }^{\mathrm{A}, \mathrm{C}}$, Kurt C. VerCauteren ${ }^{\mathrm{B}}$, Megan L. Provost $^{\mathrm{A}}$ and Anna C. Cellar ${ }^{\mathrm{A}}$ \\ A Department of Biology, Central Michigan University, Mount Pleasant, MI 48859, USA. \\ ${ }^{B}$ National Wildlife Research Center, USDA APHIS WS, Fort Collins, CO 80521, USA. \\ ${ }^{\mathrm{C}}$ Corresponding author. Email: gehri1tm@cmich.edu
}

\begin{abstract}
Context. Livestock producers worldwide are negatively affected by livestock losses because of predators and wildlifetransmitted diseases. In the western Great Lakes Region of the United States, this conflict has increased as grey wolf(Canis lupus) populations have recovered and white-tailed deer (Odocoileus virginianus) have served as a wildlife reservoir for bovine tuberculosis (Myobacterium bovis).

Aims. We conducted field experiments on cattle farms to evaluate the effectiveness of livestock-protection dogs (LPDs) for excluding wolves, coyotes (C. latrans), white-tailed deer and mesopredators from livestock pastures.

Methods. We integrated LPDs on six cattle farms (treatment) and monitored wildlife use with tracking swaths on these farms, concurrent with three control cattle farms during 2005-2008. The amount of time deer spent in livestock pastures was recorded using direct observation.

Key results. Livestock pastures protected by LPDs had reduced use by these wildlife compared with control pastures not protected by LPDs. White-tailed deer spent less time in livestock pastures protected by LPDs compared with control pastures not protected by LPDs.

Conclusions. Our research supports the theory that LPDs can be an effective management tool for reducing predation and disease transmission. We also demonstrate that LPDs are not limited to being used only with sheep and goats; they can also be used to protect cattle.

Implications. On the basis of our findings, we support the use of LPDs as a proactive management tool that producers can implement to minimise the threat of livestock depredations and transmission of disease from wildlife to livestock. LPDs should be investigated further as a more general conservation tool for protecting valuable wildlife, such as ground-nesting birds, that use livestock pastures and are affected by predators that use these pastures.
\end{abstract}

Additional keywords: bovine tuberculosis, coyote, grey wolf, livestock protection dog, mesopredators, white-tailed deer, wildlife damage management.

\section{Introduction}

Agricultural producers are important stakeholders in wildlife conservation (Kellert 1981; Conover 1998). For example, in the USA there are $\sim 2$ million farmers and ranchers, who make up $<2 \%$ of the country's population but control $\sim 40 \%$ of the land (Berg 1986; US Census Bureau 2010). Producers appreciate wildlife (Brown et al. 1978) and their support has long been recognised as essential if wildlife conservation is going to occur on private land in concert with farming and ranching (Leopold 1933). However, livestock producers worldwide, particularly smaller-scale operations, are often confronted with the challenge of reducing livestock losses to predators and wildlife-transmitted diseases. In the western Great Lakes Region of the USA, most producers are small- and medium-sized operations, with $45-59 \%$ having cattle/calf commodity sales of <US\$10000 per year, $72-85 \%$ having cattle/calf commodity sales of <US\$100000 per year, and $71-86 \%$ having $<100$ head of cattle (www.nass.usda.gov, accessed 1 June 2009). This region exemplifies challenges of maintaining agricultural production while conserving valued wildlife. Livestock depredations will likely increase as the grey wolf (Canis lupus) population increases and expands its geographic range (Mech 1995; Gehring and Potter 2005; Harper et al. 2005). The region has a large population of coyotes $(C$. latrans). Livestock producers in this region have also been affected negatively by livestock losses associated with infectious disease transmitted by wildlife. In Michigan, and more recently Minnesota, free-ranging white-tailed deer (Odocoileus virginianus, deer) continually infect cattle with bovine tuberculosis (Mycobacterium bovis, TB; Schmitt et al. 1997; Palmer et al. 2001; O’Brien et al. 2002).

Effective, producer-based management tools are needed to assist producers in reducing risk of livestock depredation and transmission of diseases such as TB to livestock (Gehring et al. 2006; VerCauteren et al. 2008). Efficacious tools that producers can adapt into their normal husbandry practices are needed to 
reduce economic losses. Lethal control, as a management tool, can be effective (Conover 2002). However, livestock depredations commonly recur annually after wolves are removed lethally following a depredation (Fritts et al. 1992; Gehring et al. 2003), and does not appear to reduce depredations at a regional scale (Musiani et al. 2005). Nonlethal management tools are regarded by society as more humane than lethal control (Reynolds and Tapper 1996; Reiter et al. 1999). Numerous non-lethal management options exist; however, few have been the subject of a controlled experiment involving free-roaming wildlife (Shivik 2006). Partly, this has been due to the difficulty in conducting large-scale experiments while controlling for confounding variables (Breck 2004; VerCauteren et al. 2008; Gehring et al. 2010a).

Livestock protection (guarding) dogs (LPDs) were developed centuries ago to protect goats and sheep from predators (Coppinger and Coppinger 2001). LPDs are generally regarded as effective in reducing livestock depredations caused by coyotes (Green et al. 1984; Andelt 1992; Andelt and Hopper 2000; Smith et al. 2000), but their effectiveness against wolves is more tenuous (Gehring et al. 2010a). VerCauteren et al. (2008) and Gingold et al. (2009) provided experimental evidence of the ability of LPDs to deter deer from livestock pastures and modify ungulate behaviour, respectively. LPDs may also have value related to the conservation of species of wildlife that are predated by species that LPDs repel. For example, Hansen and Smith (1999) documented that medium-sized mammals were excluded and/or killed by LPDs in livestock pastures, which we propose could allow species such as grassland birds to be more successful. In general, though, there is a dearth of experimental work that has evaluated the effectiveness of LPDs for reducing the use of farms by wildlife (Gehring et al. 2010a).

Our objective was to determine whether LPDs that were socialised and bonded to cattle could reduce the use of livestock pastures by wildlife, a measure of reduced risk of livestock depredation and transmission of disease to livestock. We predicted that LPDs would reduce the number of wolf, coyote, white-tailed deer and mesopredator visits into livestock pastures, and amount of time deer spent within livestock pastures.

\section{Materials and methods}

\section{Study sites}

During 2005-2008, we studied LPDs within a study area located in the western Upper Peninsula (UP) of Michigan, including Houghton, Iron, Marquette and Ontonagon counties. The study area consisted of a mixture of northern hardwoods, upland conifers, lowland conifers, agricultural areas, streams and rivers. Agriculture included cattle operations and forage crops. During the study, the UP contained 425-520 wolves within an estimated total of $\geq 87$ wolf packs (D. E. Beyer, Michigan Department of Natural Resources \& Environment, pers. comm.), as well as coyotes, deer and mesopredators interspersed within the landscape.

We selected nine beef-cattle farms on the basis of their location within the study area, habitat, livestock on pasture and their willingness to participate in the study. Farms contained 19-50 head of cattle on 10-40-ha fenced pastures. During June-September, cattle were located on pasture and confined near or in buildings for the remainder of the year. All farms were surrounded by forest and six farms included wooded areas within a portion of the pasture. All farms had existing electrified livestock fencing ( $\geq$ three electric wires and a total height of $110 \mathrm{~cm}$ ) which was used to maintain cattle within pastures. We added one electrified strand of wire $\sim 0.25 \mathrm{~m}$ from the ground and additional wires to maintain gaps $\leq 0.33 \mathrm{~m}$ at each farm (Gehring et al. 2010b). The lowest strand of wire served to improve the training of LPDs to remain within pastures on treatment farms (Gehring et al. 2010b), and control pastures also had this lower strand of wire to reduce variability among the farms as a result of fencing. Fencing on study farms was not designed to serve as predator- or deer-proof fencing and would not effectively prevent access by wolves, coyotes or deer. Dorrance and Bourne (1980) reported that coyotes still penetrated a 7 -strand electric fence they used, even though the bottom wire (15- $\mathrm{cm}$ above ground level) was electrified. Gates et al. (1978) found that 111-cm-high fencing was not effective at preventing coyotes from entering pastures. Only coyote-proof fencing (150-168-cm high with 12 strands) reduced coyote access to pastures (Gates et al. 1978; Linhart et al. 1982). VerCauteren et al. (2006) reported that common livestock-fencing designs (e.g. multi-strand electric wire fence) were not effective for excluding white-tailed deer, even with a lower electrified wire $25 \mathrm{~cm}$ from the ground.

We initially used Michigan Department of Natural Resources \& Environment (MDNRE) winter track and radio-telemetry data to identify likely study sites where wolves and farms overlapped. These areas were locations where MDNRE had monitored radio-collared wolf packs within 1-2 years of the present study. Annually, we also conducted track and scat surveys along dirt roads and on farms within these areas during late winter to early summer, to confirm the presence of wolves within $5 \mathrm{~km}$ of potential study farms. Track surveys were conducted a minimum of three times so as to confirm the presence of wolves (Wydeven et al. 1995).

We randomly assigned farms as treatment (LPDs present, $n=6$ ) or control (no LPDs present, $n=3$ ) farms. In 2007, one treatment farm was dropped from the study after the farmer ceased raising livestock. Treatment and control farms were located within $10 \mathrm{~km}$ of each other, to ensure that the wildlife within the area had equal access to both farm types. We assumed that both farm types were equally accessible to wildlife. Further, all farm pastures were confirmed to be used by wolves, coyotes, deer and mesopredators (raccoons (Procyon lotor), opossums (Didelphis virginiana), red fox (Vulpes vulpes) and striped skunks (Mephitis mephitis)), on the basis of our track surveys conducted before the experiment began.

\section{Dog training and integration with cattle}

In March 2005, we purchased 7-8-week-old Great Pyrenees pups (6 females, 6 males) from a reputable breeder that had an established record of producing working LPDs. Subsequently, we placed a male-female pair of pups at each treatment farm. We provided producers with a document of training guidelines and, with our assistance, they were responsible for the care and training of their pups. Within a livestock barn, pups were housed in a $2 \times 4$-m pen (LPD pen) located within a livestock pen $(8 \times 8 \mathrm{~m})$ that contained two $\leq 1$-week-old calves. We provided food and 
water in the LPD pen that only the dogs had access to. Pups could move in and out of the LPD pen to interact and bond with calves (Gehring et al. 2010b). We limited human contact with pups for a strong bond to develop with cattle and not humans (VerCauteren et al. 2008). However, pup interactions with calves were monitored to detect inappropriate behaviours (e.g. biting calves, pulling tails or playing aggressively), and these behaviours were corrected immediately. At 4 months, pups were allowed to interact with adult cattle in barns under direct supervision by producers. If taken outside, pups were on leashes and allowed only in the area they would be guarding as adults. At 6 months, pups were neutered or spayed to reduce the likelihood of hormonal changes from influencing their effectiveness as LPDs, including roaming behaviour (VerCauteren et al. 2008).

At 7 months, we began a slow-release program for integrating pups with adult cattle in pastures. During the day, pups were housed with their calves in outdoor pens $(5 \times 5 \mathrm{~m})$ within pastures and then returned to their livestock barn by dusk. Pups were walked daily on leashes around the inside of pastures to familiarise them with the pasture and to establish the fence as a boundary. Pups were encouraged to interact with the adult cattle while exploring pastures. This slow-release program allowed the pups to become accustomed to living in a new area, while furthering the bonding between the adult cattle and the pups (Gehring et al. 2010b).

Before pups were released into pastures, we added a strand of 12-gauge electric fence wire to the existing fence at treatment and control farms to maintain a bottom wire $0.25 \mathrm{~m}$ from the ground at each farm (Gehring et al. 2010b). We monitored fencing regularly and maintained it at $7000 \mathrm{~V}$. Throughout the study, if a dog escaped and began roaming, we installed an invisible fencing system (PetSafe Stubborn Dog System, Radio Systems Corporation, Auburn, IN, USA) and put a shock collar on the LPD to ensure it stayed in the pasture (Gehring et al. 2010b).

\section{Wildlife visitation on farms}

We recorded visits by wolves, coyotes, deer and mesopredators at treatment and control farms by using track swaths. We created track swaths by clearing a $1.5 \times 4-\mathrm{m}$ area of debris and vegetation and sifting soil over the area. Track swaths were placed at 200-m intervals around the entire perimeter of each pasture, with equal proportions inside and outside the pasture (i.e. straddling the livestock fencing). No attractant was used at track swaths. Surveys of track swaths were conducted biweekly during May to August, with treatment and control farms being monitored concurrently during the 6-day sampling periods. This resulted in a total of 24 sample days each year. During each check of track swaths, tracks were identified and recorded as a single visitation if the track proceeded into the pasture. We identified tracks using shape characteristics and track dimensions (Halfpenny and Bruchac 2001). We used a cut-off point in track size of $9.0 \mathrm{~cm}$ in length and $7.0 \mathrm{~cm}$ in width to differentiate coyote and wolf tracks. Domestic-dog and wild-canid tracks were differentiated on the basis of size and shape (e.g. length : width ratio) characteristics (Halfpenny and Bruchac 2001). Track swaths were raked smooth after each check to prevent double counting. Annual visitation data were standardised by summing the number of tracks entering the pasture for each farm and dividing by the number of sampling days. This provided an index of species-specific visitation by wildlife to farms, a measure of intensity of use and potential risk.

During 22-25 June 2006, we conducted ground-nesting bird and nest surveys on two treatment and two control farms. We used a drag line to flush birds and walked 20-m-wide transects throughout the herbaceous portions of pastures. Locations of flushed birds were marked with a wire flag and the area was searched to find a nest. The number of flushed birds and nests was recorded and summed for each pasture. Because of a small sample size (i.e. two treatment and two control farms), we did not conduct statistical analyses to compare treatment and control farms for the number of birds flushed or the number of nests.

During June-August 2007 and 2008, we also used direct observation to measure the amount of time deer spent in livestock pastures on four treatment and three control farms. We observed pastures for $2 \mathrm{~h}$ at each farm once per week for 7 weeks, from $1 \mathrm{~h} 40 \mathrm{~min}$ before to $20 \mathrm{~min}$ after the sunset. We used binoculars and a stop-watch to record observations from a parked vehicle outside the pasture, at positions that allowed the pasture area to be viewed without obstruction. We recorded the time when a deer or group of deers entered the pasture until the time they left the pasture. The total number of minutes deers spent in pastures at each farm was standardised as the number of minutes per 2-h sample period for each farm. Our research was approved by the Institutional Animal Care and Use Committee at Central Michigan University (IACUC \#13-04).

\section{Statistical analysis}

We used a two-way Friedman's test and repeated-measures ANOVA (Conover and Iman 1981) for wolf, coyote and deer visits to livestock pastures. We blocked by farm type (treatment or control) and time (year). We excluded data from 2005 in our analyses because no LPDs were yet present on farms. We used a Wilcoxon rank-sum test to compare mesopredator visits on treatment and control farms during 2006, the first year LPDs were present. We used a Wilcoxon rank-sum test to compare treatment and control farms relative to deer use (time spent in pastures) during 2007 and 2008. We conducted statistical analyses with SAS statistical software (SAS Institute, Cary, NC, USA). We used a significance level of $\alpha=0.05$.

\section{Results}

We found a group effect (i.e. between-subject effect) for wolf, coyote and deer visitation. Treatment farms had fewer visits by wolves $(F=28.57, P<0.001)$, coyotes $(F=5.69, P=0.027)$, and deer $(F=4.34, P=0.047)$ than did the control farms. We did not find a time effect for wolves $(F=1.43, P=0.263)$, coyotes $(F=0.87, P=0.435)$, or deer $(F=0.21, P=0.888)$. We recorded wolves only ever on treatment farms in 2005, the year before LPDs were present. During 2005, coyote $(\mathrm{S}=15, P=0.560$, Fig. 1), deer ( $\mathrm{S}=15.5, P=0.488$, Fig. 2) and mesopredator $(\mathrm{S}=14.5, P=0.548$, Fig. 3) visitation was similar on treatment and control farms. Once LPDs were present, wolf and coyote visitation declined to zero on treatment farms, and increased slightly on control farms (Fig. 1). Further, no 

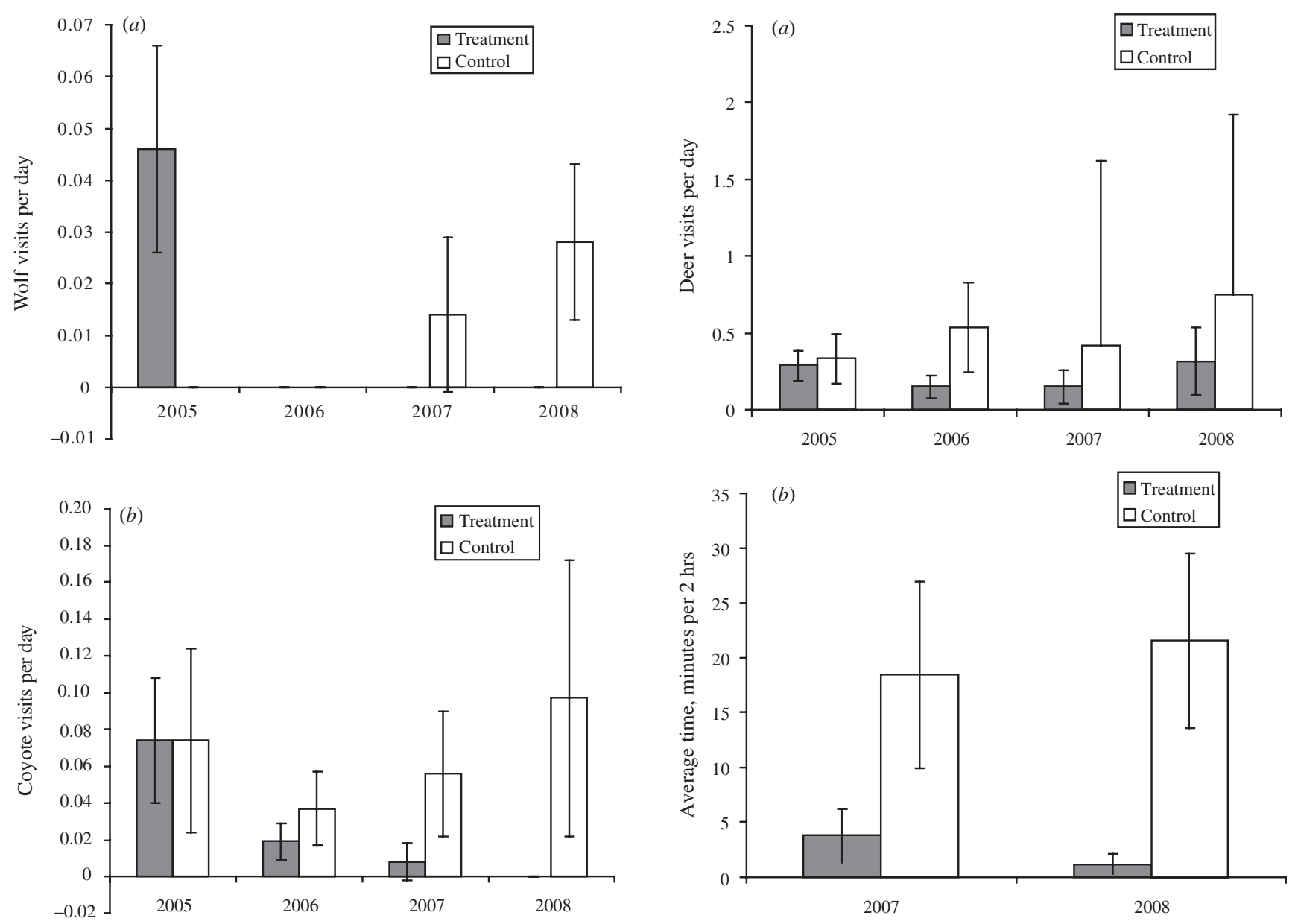

Fig. 1. Mean ( \pm 1 s.e.) number of $(a)$ wolf and $(b)$ coyote visits per day into livestock pastures on study farms in the western Upper Peninsula of Michigan, May-August 2005-2008. No livestock-protection dogs (LPDs) were present in pastures during 2005. LPDs were present on treatment farms during 2006-2008.

livestock depredations occurred on our treatment farms, whereas neighbouring farms experienced depredations. Deer visitation was lower on treatment than on control farms, and remained relatively stable throughout time (Fig. 2). We noted a slight decrease in mesopredator visits to treatment farms during the first year that LPDs were present, compared with control farms ( $\mathrm{S}=21, P=0.083$, Fig. 3). Our personal observations and farmer accounts noted cases of LPD-killed mesopredators (raccoons, opossums, foxes and skunks) on protected pastures. We recorded 14 birds and four nests on treatment farms, whereas we recorded 14 birds and zero nests on control farms.

The amount of time deer spent on treatment pastures was not different from the time spent on control pastures during 2007 $(\mathrm{S}=16, P=0.114)$, whereas they spent less time in treatment than on control pastures during $2008(\mathrm{~S}=6, P=0.050)$. During 2007 and 2008, deer spent an average of $3.8 \mathrm{~min}$ and $1.2 \mathrm{~min}$ on treatment pastures compared with $18.4 \mathrm{~min}$ and $21.6 \mathrm{~min}$, respectively, on control pastures (Fig. 2). During 2007, one treatment farm accounted for $67 \%$ of total time deer spent on treatment farm pastures. In one case, deer were visually

Fig. 2. Mean ( \pm 1 s.e.) number of $(a)$ deer visits per day into livestock pastures and $(b)$ amount of time deer spent in pastures on study farms in the western Upper Peninsula of Michigan, May-August 2005-2008. No livestock-protection dogs (LPDs) were present in pastures during 2005. LPDs were present on treatment farms during 2006-2008.

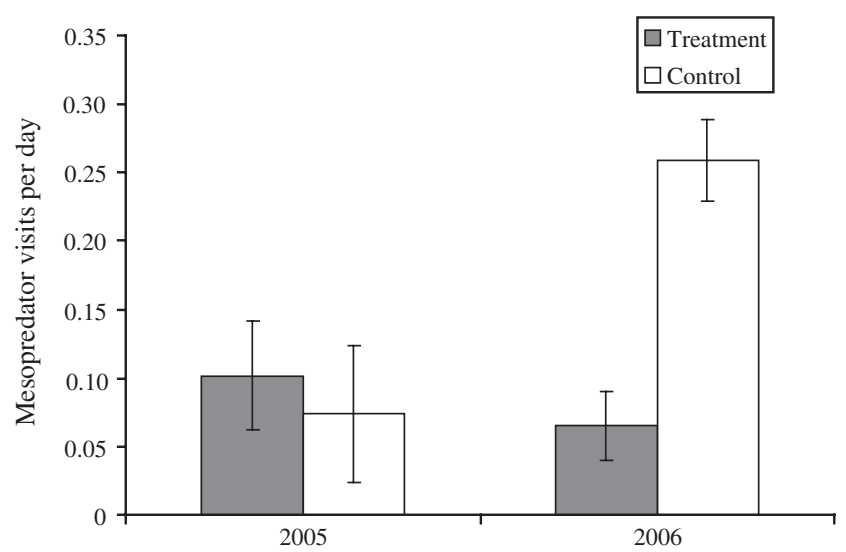

Fig. 3. Mean ( \pm 1 s.e.) number of mesopredator visits per day into livestock pastures on study farms in the western Upper Peninsula of Michigan, May-August 2005-2006. No livestock-protection dogs (LPDs) were present in pastures during 2005. LPDs were present on treatment farms during 2006. 
obstructed from the LPDs by forest cover and went undetected for $1 \mathrm{~h}$.

\section{Discussion}

The effectiveness of LPDs has primarily been evaluated for predators, and more recently it has been assessed for ungulates. Among predator-based studies, most have relied on producer-based reporting and surveys, rather than field experimentation (Gehring et al. 2010a). We found only one field trial evaluating LPD efficacy with wolves (cited in Coppinger et al. 1988; Coppinger and Coppinger 1996). This study suggested that LPDs displayed protective behaviour against free-ranging wolves and defended experimenter-created bait stations. However, sample size was small and the researchers did not make direct observations on LPD behaviour while defending the bait stations. Linhart et al. (1979) provided the only field-trial evidence of the effectiveness of LPDs against coyotes. They found that LPDs reduced sheep depredations by coyotes on three ranches over a 20-day period, and coyotes appeared to be displaced from ranches for an additional 20 days after the LPDs were removed. Our study demonstrated reduced use of livestock pastures by wolves and coyotes, with visitation indices declining to zero. As such, we suggest that LPDs can be effective for reducing the risk of livestock depredations by wolves and coyotes on pastures associated with small- and medium-sized cattle farms.

VerCauteren et al. (2008) were the first to use an experimental design to examine LPDs in a novel application for deterring potentially infectious deer. They found that LPDs were effective at reducing the use of livestock pastures and consumption of livestock feed by deer. Shared use of concentrated livestock feed (Palmer et al.2004) is a primary route of transmission of TB from deer to cattle (O'Brien et al. 2006). Gingold et al. (2009) found that LPDs modified the behaviour, movements and reproductive success of mountain gazelles (Gazella gazella) present in their study area. Our study demonstrated reduced use of livestock pastures by deer. We also demonstrated reduced time deer spent on pastures during one year. Our results support the assertion of VerCauteren et al. (2008) that LPDs may reduce the potential for disease transmission between deer and cattle by reducing the use of and time spent on pastures by deer. Our study also expands this assertion to moderately sized livestock operations.

Medium-sized mammals also have been excluded and/or killed by LPDs on livestock pastures (Hansen and Smith 1999). Our study noted a slight decrease in mesopredator visitation to livestock pastures during the first year when LPDs were present. We failed to continue monitoring mesopredator activity for subsequent years. Thus, we are not certain whether LPD effectiveness for deterring mesopredators would have increased as the dogs matured and became better protectors. We obtained preliminary field data that suggested that control pastures had fewer ground-nesting bird nests, possibly because of greater rates of nest predation from mesopredators, than did LPD-protected pastures (Gehring et al. 2010a). Thus, LPDs might also serve as a more general tool for wildlifeconservation objectives, such as reducing mortality of groundnesting birds by limiting pasture use by mammalian species of wildlife. However, more research is needed on this topic.
The soil track swaths we used were a passive method for monitoring wildlife visitation. Visitation rates for predators were low, yet we showed a difference between treatment and control farms. We were unable to determine whether higher levels of predator visitation would be deterred by LPDs. We suggest that some wildlife visits into pastures should not be construed as a measure of LPD ineffectiveness. Our track swaths did not measure the outcome of wildlife trespasses into pastures. LPDs would still be effective if they chase out wildlife and limit interactions between wildlife and livestock. Also, imperfect detection of wildlife by LPDs may allow wildlife to temporarily use pastures, which likely explains the equal amounts of time deer spent on treatment and control pastures during 2007.

VerCauteren et al. (2008) estimated that the cost of LPDs was US\$850 per year, assuming a 10-year effective working life of dogs (Green et al. 1994; Green and Woodruff 1999). Our purchase price for LPDs was US\$400 per dog, monthly maintenance costs (food and veterinary care) were US\$50 per dog, and farmer-assisted training costs during the first year (paid graduate-student assistant) was US $\$ 4000$. Thus, our estimated cost of each LPD applied in our study was US $\$ 1040$ per year. In addition to cost considerations, the application of LPDs to farms requires livestock producers that are genuinely interested in using LPDs and fully committed to proper training and maintenance of the dogs (Gehring et al. 2010b). We deem the assistance provided to farmers during the first year as important in successfully integrating LPDs.

Our results have provided evidence that LPDs are an effective non-lethal management tool for deterring wolves, coyotes and deer from livestock pastures. LPDs may have a more general application of protecting livestock and pastures from a range of wildlife species, and appear to be a very versatile and general conservation tool for managing wildlife-human conflict issues. LPDs could serve as a valuable, pro-active management tool producers could implement into their normal livestock husbandry to help reduce livestock losses from predators and wildlife diseases. LPDs also may be a more general conservation tool for excluding mesopredators from pastures, thereby reducing rates of nest predation on ground-nesting birds, although more research is needed on this issue. Although the utility of LPDs is clear and we advocate their application, additional research is required to better determine how to maximise their efficacy. Questions to explore include evaluating the number of LPDs needed relative to pasture size, wildlife species present and the level of motivation of wildlife to enter pastures.

\section{Acknowledgements}

Our study was funded by Central Michigan University (Research Excellence Fund Award), Central Michigan University College of Graduate Studies, USDA-APHIS-WS-National Wildlife Research Center, USDA - Sustainable Agriculture Research and Education Program, Animal Welfare Institute (Christine Stevens Wildlife Award), CITGO Petroleum, Inc., Defenders of Wildlife, and National Geographic Society-Conservation Trust. Logistical support was provided by Michigan Department of Natural Resources \& Environment, USA Forest Service, and the Warren family. We are grateful to livestock producers who participated in this study and to A. Boetcher, R. Brown, J. Detraz, K. Luzinski and J. Pejza for valuable field assistance. We thank B. Swanson, D. Uzarski and D. Woolnough for assistance with 
statistical analyses and two anonymous reviewers for comments that improved the manuscript.

\section{References}

Andelt, W. F. (1992). Effectiveness of livestock guarding dogs for reducing predation on domestic sheep. Wildlife Society Bulletin 20, 55-62.

Andelt, W. F., and Hopper, S. N. (2000). Livestock guard dogs reduce predation on domestic sheep in Colorado. Journal of Range Management 53, 259-267. doi:10.2307/4003429

Berg, N. A. (1986). USDA goals for strengthening private land management in the 1980s. In 'Transactions of the North American Wildlife and Natural Resources Conference'. (Ed. R. E. McCabe.) pp. 137-145. (Wildlife Management Institute: Washington, DC.)

Breck, S. W. (2004). Minimizing carnivore-livestock conflict: the importance and process of research in the search for coexistence. In 'People and Predators: from Conflict to Coexistence'. (Eds N. Fascione, A. Delach and M. Smith.) pp. 13-27. (Island Press: Washington, DC.)

Brown, T. L., Decker, D. J., and Dawson, C. P. (1978). Willingness of New York farmers to incur white-tailed deer damage. Wildlife Society Bulletin 6, 235-239.

Conover, M. R. (1998). Perceptions of American agricultural producers about wildlife on their farms and ranches. Wildlife Society Bulletin $\mathbf{2 6}$, 597-604.

Conover, M. R. (2002). 'Resolving Human-Wildlife Conflicts: the Science of Wildlife Damage Management.' (Lewis Publishers: Boca Raton, FL.)

Conover, W. J., and Iman, R. L. (1981). Rank transformations as a bridge between parametric and nonparametric statistics. American Statistician 35, 124-129. doi:10.2307/2683975

Coppinger, R., and Coppinger, L. (1996). Interactions between livestock guarding dogs and wolves. In 'Ecology and Conservation of Wolves in a Changing World'. (Eds L. N. Carbyn, S. H. Fritts and D. R. Seip.) pp. 523-526. (Canadian Circumpolar Institute: Edmonton, Canada.)

Coppinger, R., and Coppinger, L. (2001). 'Dogs: a New Understanding of Canine Origin, Behavior, and Evolution.' (The University of Chicago Press: Chicago, IL.)

Coppinger, R., Coppinger, L., Langeloh, G., Gettler, L., and Lorenz, J. (1988). A decade use of livestock guarding dogs. In 'Proceedings of the 13th Vertebrate Pest Conference'. (Eds A. C. Crabb and R. E. Marsh.) pp. 209-214. (University of California: Davis, CA.)

Dorrance, M. J., and Bourne, J. (1980). An evaluation of anti-coyote electric fencing. Journal of Range Management 33, 385-387. doi:10.2307/ 3897890

Fritts, S. H., Paul, W. J., Mech, L. D., and Scott, D. P. (1992). Trends and management of wolf-livestock conflicts in Minnesota. US Fish and Wildlife Service Resource Publication No. 181. (US Fish and Wildlife Service: Washington, DC.)

Gates, N. L., Rich, J. E., Godtel, D. D., and Hulet, C. V. (1978). Development and evaluation of anti-coyote electric fencing. Journal of Range Management 31, 151-153. doi:10.2307/3897668

Gehring, T. M., and Potter, B. A. (2005). Wolf habitat analysis in Michigan: an example of the need for proactive land management for carnivore species. Wildlife Society Bulletin 33, 1237-1244. doi:10.2193/00917648(2005)33[1237:WHAIMA]2.0.CO;2

Gehring, T. M., Kohn, B. E., Gehring, J. L., and Anderson, E. M. (2003). Limits to plasticity in gray wolf, Canis lupus, pack structure: conservation implications for recovering populations. Canadian Field Naturalist 117, 419-423.

Gehring, T. M., Hawley, J. E., Davidson, S. J., Rossler, S. T., Cellar, A. C., Schultz, R. N., Wydeven, A. P., and VerCauteren, K. C. (2006). Are viable non-lethal management tools available for reducing wolf-human conflict? Preliminary results from field experiments. In 'Proceedings of the 22nd Vertebrate Pest Conference'. (Eds R. M. Timm and J. M. O'Brien.) pp. 2-6. (University of California: Davis, CA.)
Gehring, T. M., VerCauteren, K. C., and Landry, J.-M. (2010a). Livestock protection dogs in the 21 st century: is an ancient tool relevant to modern conservation challenges? Bioscience 60, 299-308. doi:10.1525/bio. 2010.60.4.8

Gehring, T. M., VerCauteren, K. C., and Cellar, A. C. (2010b). Good fences make good neighbors: implementation of electric fencing for establishing effective livestock protection dogs. Human-Wildlife Interactions 4, 144-149.

Gingold, G., Yom-Tov, Y., Kronfeld-Schor, N., and Geffen, E. (2009). Effect of guard dogs on the behavior and reproduction of gazelles in cattle enclosures on the Golan Heights. Animal Conservation 12, 155-162. doi:10.1111/j.1469-1795.2009.00235.x

Green, J. S., and Woodruff, R. A. (1999). Livestock guarding dogs: protecting sheep from predators. Agricultural Information Bulletin No. 588. (US Department of Agriculture: Washington, DC.)

Green, J. S., Woodruff, R. A., and Tueller, T. T. (1984). Livestock guarding dogs for predator control: costs, benefits, and practicality. Wildlife Society Bulletin 12, 44-50.

Green, J. S., Woodruff, R. A., and Andelt, W. F. (1994). Do livestock guarding dogs lose their effectiveness over time? Proceedings of the Vertebrate Pest Conference 16, 41-44.

Halfpenny, J. C., and Bruchac, J. (2001). 'Scat and Tracks of the Northeast: a Field Guide to the Signs of Seventy Wildlife Species.' (Falcon: Guilford, CT.)

Hansen, I., and Smith, M. E. (1999). Livestock-guarding dogs in Norway. Part II: different working regimes. Journal of Range Management $\mathbf{5 2}$, 312-316. doi:10.2307/4003539

Harper, E. K., Paul, W. J., and Mech, L. D. (2005). Causes of wolf depredation increase in Minnesota from 1979-1998. Wildlife Society Bulletin 33, 888-896. doi:10.2193/0091-7648(2005)33[888:COWDIM] 2.0.CO;2

Kellert, S. R. (1981). Wildlife and the private landowner. In 'Proceedings of the Wildlife Management on Private Lands Symposium'. (Eds R. T. Dumke, G. V. Berger and J. R. March.) pp. 18-34. (LaCrosse Printing Company: LaCrosse, WI.)

Leopold, A. (1933). 'Game Management.' (Charles Scribner's and Sons: New York.)

Linhart, S. B., Sterner, R. T., Carrigan, T. S., and Henne, D. R. (1979). Komondor guard dogs reduce sheep losses to coyotes: a preliminary evaluation. Journal of Range Management 32, 238-241. doi:10.2307/ 3897131

Linhart, S. B., Roberts, J. D., and Dasch, G. J. (1982). Electric fencing reduces coyote predation on pastured sheep. Journal of Range Management 35, 276-281. doi:10.2307/3898301

Mech, L. D. (1995). The challenge and opportunity of recovering wolf populations. Conservation Biology 9, 270-278. doi:10.1046/j.15231739.1995.9020270.x

Musiani, M., Muhly, T., Gates, C. C., Callaghan, C., Smith, M. E., and Tosoni, E. (2005). Seasonality and reoccurrence of depredation and wolf control in western North America. Wildlife Society Bulletin 33, 876-887. doi:10.2193/0091-7648(2005)33[876:SARODA]2.0.CO;2

O'Brien, D. J., Schmitt, S. M., Fierke, J. S., Hogle, S. A., Winterstein, S. R., Cooley, T. M., Moritz, W. E., Diegel, K. L., Fitzgerald, S. D., Berry, D. E., and Kaneene, J. B. (2002). Epidemiology of Mycobacterium bovis in free-ranging white-tailed deer, Michigan, USA, 1995-2000. Preventive Veterinary Medicine 54, 47-63. doi:10.1016/S0167-5877 (02)00010-7

O’Brien, D. J., Schmitt, S. M., Fitzgerald, S. D., Berry, D. E., and Hickling, G. J. (2006). Managing the wildlife reservoir of Mycobacterium bovis: the Michigan, USA, experience. Veterinary Microbiology 112, 313-323. doi:10.1016/j.vetmic.2005.11.014

Palmer, M. V., Whipple, D. L., and Waters, W. R. (2001). Experimental deer-to-deer transmission of Mycobacterium bovis. American Journal of Veterinary Research 62, 692-696. doi:10.2460/ajvr.2001.62.692 
Palmer, M. V., Waters, W. R., and Whipple, D. L. (2004). Investigation of the transmission of Mycobacterium bovis from deer to cattle through indirect contact. American Journal of Veterinary Research 65, 1483-1489. doi:10.2460/ajvr.2004.65.1483

Reiter, D. K., Brunson, M. W., and Schmidt, R. H. (1999). Public attitudes toward wildlife damage management and policy. Wildlife Society Bulletin 27, 746-758.

Reynolds, J. C., and Tapper, S. C. (1996). Control of mammalian predators in game management and conservation. Mammal Review 26, 127-155. doi:10.1111/j.1365-2907.1996.tb00150.x

Schmitt, S. M., Fitzgerald, S. D., Cooley, T. M., Bruning-Fann, C. S., Sullivan, L., Barry, D., Carlson, T., Minnis, R. B., Payeur, J. B., and Sikarskie, J. (1997). Bovine tuberculosis in free-ranging white-tailed deer from Michigan. Journal of Wildlife Diseases 33, 749-758.

Shivik, J. A. (2006). Tools for the edge: what's new for conserving carnivores. Bioscience 56, 253-259. doi:10.1641/0006-3568(2006)056[0253: TFTEWN]2.0.CO;2

Smith, M. E., Linnell, J. D. C., Odden, J., and Swenson, J. E. (2000). Review of methods to reduce livestock depredation: I. Guardian animals. Acta Agriculturae Scandinavica, Section A. Animal Science 50, 279-290.
US Census Bureau (2010). 'Statistical Abstract of the United States.' 129th edn. (US Government Printing Office: Washington, DC.)

VerCauteren, K. C., Lavelle, M. J., and Hygnstrom, S. (2006). Fences and deer-damage management: a review of designs and efficacy. Wildlife Society Bulletin 34, 191-200. doi:10.2193/0091-7648(2006)34[191: FADMAR]2.0.CO;2

VerCauteren, K. C., Lavelle, M. J., and Phillips, G. E. (2008). Livestock protection dogs for deterring deer from cattle and feed. Journal of Wildlife Management 72, 1443-1448. doi:10.2193/2007-372

Wydeven, A. P., Schultz, R. N., and Thiel, R. P. (1995). Monitoring of a recovering gray wolf population in Wisconsin, 1979-1991. In 'Ecology and Conservation of Wolves in a Changing World'. (Eds L. N. Carbyn, S. H. Fritts and D. R. Seip.) pp. 147-156. (Canadian Circumpolar Institute: Edmonton, Canada.)

Manuscript received 12 February 2010, accepted 16 July 2010 